Article

\title{
Improving Sustainability of the Griess Reaction by Reagent Stabilization on PDMS Membranes and ZnNPs as Reductor of Nitrates: Application to Different Water Samples
}

\author{
Lusine Hakobyan (D), Belén Monforte-Gómez, Yolanda Moliner-Martínez, Carmen Molins-Legua *(D) \\ and Pilar Campíns-Falcó *(D)
}

Citation: Hakobyan, L.;

Monforte-Gómez, B

Moliner-Martínez, Y.; Molins-Legua,

C.; Campíns-Falcó, P. Improving

Sustainability of the Griess Reaction by Reagent Stabilization on PDMS

Membranes and ZnNPs as Reductor of Nitrates: Application to Different Water Samples. Polymers 2022, 14, 464 https://doi.org/10.3390/ polym14030464

Academic Editor: Alessio Fuoco

Received: 17 December 2021

Accepted: 20 January 2022

Published: 24 January 2022

Publisher's Note: MDPI stays neutral with regard to jurisdictional claims in published maps and institutional affiliations.

Copyright: (C) 2022 by the authors. Licensee MDPI, Basel, Switzerland. This article is an open access article distributed under the terms and conditions of the Creative Commons Attribution (CC BY) license (https:// creativecommons.org/licenses/by/ $4.0 /)$
MINTOTA Research Group, Departament de Química Analítica, Facultat de Química, Universitat de València, Dr. Moliner 50, 46100 Valencia, Spain; lusine.hakobyan@uv.es (L.H.); mongobe@alumni.uv.es (B.M.-G.); yolanda.moliner@uv.es (Y.M.-M.)

* Correspondence: cmolins@uv.es (C.M.-L.); pilar.campins@uv.es (P.C.-F.)

\begin{abstract}
A new approach based on the use of polydimethylsiloxane (PDMS) membranes doped with Griess reagents for in situ determination of $\mathrm{NO}_{2}^{-}$and $\mathrm{NO}_{3}^{--}$in real samples is proposed. The influence of some doping compounds, on the properties of the PDMS membranes, such as tetraethyl orthosilicate (TEOS), or / and ionic liquids $\left(\mathrm{OMIM} \mathrm{PF}_{6}\right)$ has been studied. Membrane characterization was performed. To apply the procedure to $\mathrm{NO}_{3}^{-}$determination, dispersed $\mathrm{Zn}$ nanoparticles (ZnNPs) were employed. The analytical responses were the absorbance or the RGB components from digital images. Good precision (RSD $<8 \%$ ) and detection limit of 0.01 and $0.5 \mathrm{mgL}^{-1}$ for $\mathrm{NO}_{2}^{-}$and $\mathrm{NO}_{3}^{-}$ respectively, were achieved. The approach was satisfactory when applied to the determination of $\mathrm{NO}_{2}^{-}$and $\mathrm{NO}_{3}^{-}$in drinking waters, irrigation and river waters, and waters from canned and fresh vegetables. The results obtained were statistically comparable with those by using nitrate ISE or UV measurement. This approach was transferred satisfactory to 96 wells for multianalysis. This study enables the improvement in the on-site determination of $\mathrm{NO}_{2}^{-}$and $\mathrm{NO}_{3}^{-}$in several matrices. It is a sustainable alternative over the reagent derivatizations in solution and presents several advantages such as being versatile, simplicity, low analysis time, cost, and energy efficiency. The response can be detected visually or by portable instruments such as smartphone.
\end{abstract}

Keywords: PDMS membranes; embedded Griess reagent; ionic liquid; ZnNPs; nitrate and nitrite; smartphone; digital imagen; colorimetry; real samples; 96 wells

\section{Introduction}

Nitrite and nitrate are widely present in environmental samples like water, soil, food and agricultural products. Elevated concentrations of nitrate in water systems pose a significant risk to the environment and to human health [1]. The quantity of nitrates in waters and soil contribute to the amount in vegetables and fruits. Vegetables are the most important source of nitrate exposure in the human diet and contribute to the intake of more than $80 \%$ of nitrates [2]. In Table 1 are summarized the main regulations about nitrate concentration in water and in some foods (vegetables) [3-8]. The maximum nitrate amount to be ingested daily is less than $3.65 \mathrm{mg} \mathrm{kg}^{-1}$ by body weight [9]. Because of this concern, during the past 15 years, numerous methods have been reported for the detection and determination of nitrite and/or nitrate including spectrophotometric, chemiluminescent, electrochemical, chromatographic, capillary electrophoresis, spectrofluorometric and electrochemiluminescence methods [10]. Moreover, several reviews have been published [10,11]. Among these methods, the spectroscopic methods have excellent detection limits and have facile protocols. These methods are by far the most widely used due to its simplicity and cheapness. The well-known spectrophotometric method for analysis of nitrite is based on the Griess reaction [12]. Often the protocols described for this determination indicate that the 
procedure should be carried out in the laboratory either in batch or continuous mode (flow injection analysis). These methodologies are far from the actual needs of analytical methods that combine high sensitivity, accuracy and rapid analysis with simplicity, portability, low cost and access for non-qualified citizen groups. Thus, to develop in situ procedures, the Griess reaction presents some weak points, such as (i) the reagents being added in solution and (ii) the determination of nitrate required its reduction to nitrite. Concerning to Griess reagents, these are rather unstable and usually need to be keeping at low temperatures as individual solutions. One option to stabilize reagents is to embed them in solid supports; materials such as polymers can be used as an inert matrix support [13,14]. This approach is being used for the development of optical sensors and microfluidic devices [15-18]. These strategies generally allow the miniaturization, reduce reagent and waste, cost, not requiring any external forces, and they can be used for in situ analysis by non-trained personal. Moreover, the reagent entrapment during the polymeric gelation process has certain advantages such as greater resistance of the membrane or a better preservation of the reagent against environmental conditions. Campíns-Falco et al. [16-18] have entrapped reagents such as 1,2-Naftoquinone sulphonate (NQS) or tetramethylbencidine (TMB) in PDMS matrix with satisfactory results. Bhakta S.A. et al. proposed a paper colorimetric test for $\mathrm{NO}_{2}^{-}$using paper and for which several alternatives have been studied to avoid the deterioration of the reagent [19]. We selected PDMS as and hydrofobic material to protect the reagent. The reagents keep all the properties when PDMS was used as supporting material. These membranes can be doped with ionic liquid to enhance the permeability of gaseous analytes (ammonia) [20]. Doped polymeric reactions can be used for catalytic reactions, this is the case of polysulfone membranes doped with ionic liquid [21], or polybenzimidazole-based nanofiltration membrane doped with azido derivatized cinchona-squaramide bifunctional catalyst [22].

Table 1. Concentrations limits of nitrate or nitrite established by different regulations.

\begin{tabular}{cccc}
\hline Sample & Limit NO $_{3}^{-}$ & Limit NO $_{2}^{-}$ & Regulation \\
\hline Drinking water & $50 \mathrm{mg} \mathrm{L}^{-1}$ & $0.5 \mathrm{mgL}^{-1}$ & $\begin{array}{c}\text { Council Directive 98/83/EC of 3 November 1998 } \\
\text { EPA-United States Environmental Protection } \\
\text { Agency WHO-World Health Organization }\end{array}$ \\
$\begin{array}{c}\text { Groundwater } \\
\text { Sewage treatment plant }\end{array}$ & $50 \mathrm{mg} \mathrm{L}^{-1}$ & - & $\begin{array}{c}\text { Directive 2006/118/EC of the European Parliament } \\
\text { and of the Council of 12 December 2006 } \\
\text { Spanish regulation, Royal Decree 1620/2007 of } \\
\text { 7 December }\end{array}$ \\
$\begin{array}{c}\text { Fresh spinach } \\
\begin{array}{c}\text { Preserved, deep-frozen, or } \\
\text { frozen spinach }\end{array}\end{array}$ & $2500-3000 \mathrm{mg} \mathrm{L} \mathrm{kg}^{-1}$ & - & $\begin{array}{c}\text { Commission Regulation (EC) N 1881/2006 of } \\
\text { 19 December 2006 }\end{array}$ \\
\hline
\end{tabular}

Concerning to the nitrate reduction to nitrite, enzymatic reduction using nitrate reductase or photochemical reduction through the use of UV light can be used; however, these methods typically offer poor reproducibility [23]. Other studies have focused on the nitrate reduction approaches using a column of $\mathrm{Zn}$ granules or a copper-coated cadmium column $[24,25]$ hydrazide with copper catalyst [26] photo-induced device, etc. Vanadium III chloride as reductant has also been proposed $[27,28]$. Many of these procedures are performed on-line by using flow injection analysis (FIA) to control the reduction process and the derivatization step. In reference to in situ procedures Martínez-Cisneros et al. [29] proposed a lab on a chip procedure using a column of cadmium and Griess reaction. M. Jayawardane et al. [30] used immobilized $\mathrm{Zn}$ dust for the reduction reaction and developed a microfluidic paper-based procedure. In recent years, the use of nanoparticles has aroused great interest for their especial properties. As far as we know no work has been published using NPs as reductor of nitrates combined with Griess reaction. 
In the present work we present an in situ, low-cost, robust sensor based on Griess reagents entrapped in a polymeric composite as a delivery reagent support (membrane). Due to the higher porosity, PDMS doped with liquid ionic has been selected as a composite. Additionally, the reduction capacity of non-toxic ZnNPs on the reduction reaction of nitrate has been studied. The optimized procedure has been successfully applied to determine nitrite and nitrate in several real samples (water from different sources, and water from canned vegetables and boiled fresh vegetables). A comparison with other methods reported in the literature has been performed. This method simplifies the analytical protocol and reduces the toxicity and manipulation of solutions. This is a fast procedure that can be used as a single assay or in a multiple assay by using microplate (e.g., 96 wells) with reagent-PDMS-membranes settled at the bottom of the wells. The analytical responses were obtained by measuring the absorbance or by using the RGB components from digital images obtained with a smartphone.

\section{Materials and Methods}

\subsection{Reagents and Solutions}

Ultrapure water obtained using a Nanopure II system (Barnstead, NH, USA) was employed for the preparation and dilution of all the solutions. PDMS membranes were synthesized by using Sylgard ${ }^{\circledR} 184$ Silicone Elastomer Kit (base and curing agent) obtained by Dow Corning (Midland, MI, USA). Tetraethyl orthosilicate (TEOS $\geq 99.0 \%$ ), silicon dioxide nanoparticles $\left(\mathrm{SiO}_{2} \mathrm{NPs}, 99.5 \%\right.$, 5-15 nm particle size), $\mathrm{N}$-(1-Naphthyl) ethylenediamine dihydrochloride (NEDD), 1-methyl-3-octylimidazolium hexafluorophosphate ( $\left.\mathrm{OMIM} \mathrm{PF}_{6}\right)$, Zinc nanopowder (ZnNPs, 99\%, 40-60 nm particle size), hexadecyltrimethylammonium bromide (CTAB) were provided by Sigma-Aldrich (St. Louis, MO, USA). Sulfanilamide (SA) was obtained from Guinama (Valencia, Spain). Sodium Dodecyl Sulphate (SDS), potassium nitrate and anhydrous citric acid were provided by Panreac (Barcelona, Spain). Zn powder and sodium nitrite were purchased from Probus (Badalona, Spain). Silver nitrate was obtained from Scharlab (Barcelona, Spain).

\subsection{Apparatus}

Absorbance measurements were carried out using a Cary 60 UV-vis spectrophotometer. Spectra were recorded from 200 to $1000 \mathrm{~cm}^{-1}$. For data collection and processing, CaryWinUV software was used (Agilent Technologies, Santa Clara, CA, USA). For preparing the ZnNPs dispersion and PDMS sensors devise was employed ultrasonic bath from Sonitech. Size distributions of the $\mathrm{Zn}$ nanoparticles were determined with a Malvern Zetasizer Nano ZS from Malvern Panalytical Ltd. (Malvern, UK). A pH-meter Crison micro pH 2001, (Crison Instruments S.A., Barcelona, Spain) and a nitrate electrode were used for potentiometric measurement of nitrate. Morphology of the membrane was studied with a Hitachi S-4800 scanning electron microscope at an accelerating voltage of $20 \mathrm{keV}$, over metalized samples with a mixture of gold and palladium for $30 \mathrm{~s}$. The LG Optimus L5 II smartphone (LG, Seoul, Korea) was used to take photos of the solutions. The images were analyzed by the open-source software ImageJ. This software was employed to evaluate the color intensity of the pictures. In this model the maximum values of all the channels give rise to the white color, while if all the values are zero, black color is obtained. The quantification of the green component was chosen because it provided the best results. The color intensity obtained was converted into a value of absorbance through the expression $A=-\log B / 255$, where $B$ is the value of the coordinate and 255 represents the maximal transmitted light intensity.

\subsection{Preparation of the Composites}

\subsubsection{PDMS/TEOS-SiO ${ }_{2}$ NPs-SA-NEDD}

The fabrication of the PDMS/TEOS-SiO ${ }_{2}$ NPs-SA-NEDD composites was carried out following the procedure proposed in [13] with some modifications. Firstly, the reagents sulphanilamide (SA) $(4.18 \%)$ and N-1-Naphthyl ethylenediamine dihydrochloride (NEDD) 
(1.14\%) were added to the TEOS (39.77\%) and $\mathrm{SiO}_{2} \mathrm{NPs}(0.11 \%)$ dispersion previously prepared. The percentages of the different components were in weight. To achieve homogeneity, an ultrasonic bath was used for $5 \mathrm{~min}$. After, the final mixture was added to the elastomer base $(49.82 \%)$ and the new mixture was vigorously stirred for $15 \mathrm{~min}$ at room temperature to obtain a homogeneous suspension. Subsequently, the curing agent $(4.98 \%)$ was added to the previous solution leaving 5 min under stirring. The standard mixing ratio for PDMS was 10:1 elastomer and curing agent, respectively. This ratio provides the desirable and optimum mechanical properties. The gelation procedure was carried out at $30{ }^{\circ} \mathrm{C}$ for $8 \mathrm{~h}$, depositing $200 \mu \mathrm{L}$ of the final mixture in the well-plates $(\mathrm{d}=1.5 \mathrm{~cm})$. In case of using microplate wells, 20 ul were dropped in each well.

\subsubsection{PDMS/TEOS-SiO ${ }_{2}$ NPs-SA-NEDD-OMIM PF 6}

The preparation of the supported IL-based device was performed by mixing the reagents that form the azo compound, such as SA $(4.18 \%)$ and NEDD $(1.14 \%)$, with the $\mathrm{OMIM} \mathrm{PF}_{6}(7 \%)$. The mixture was stirred for $10 \mathrm{~min}$. After, the elastomer base $(44.2 \%)$ was added to the previous mixture and the resulting combination (combination 1) was stirred during 10 min more to get a homogeneous dispersion. Then, a mixture of TEOS-SiO ${ }_{2} \mathrm{NPs}$ was prepared by mixing $\mathrm{SiO}_{2} \mathrm{NPs}(0.11 \%)$ with TEOS (39.77\%) (combination 2). Finally, combination 1 and 2 were mixed and stirred vigorously to obtain homogenous mixture. After adding the curing agent (4.4), the mixture was stirred for $5 \mathrm{~min}$. Finally, the drying procedure was carried out as previously described (Section 2.3.1).

\subsubsection{PDMS $/ \mathrm{SiO}_{2} \mathrm{NPs}$ SA-NEDD-OMIM $\mathrm{PF}_{6}$}

The procedure followed was like that described in Section 2.3.2, however, in this case the TEOS was not included in the membrane. The proportion of the elastomer base was $84.04 \%$.

\subsubsection{Preparation of ZnNPs Dispersion}

Solutions of surfactants in water were prepared by weighing the appropriate amounts of CTAB and SDS for final concentrations $15 \mathrm{mM}$ and $17.3 \mathrm{mM}$, respectively. Mixtures of CTAB and SDS were prepared by mixing the proportions CTAB70\% $-\mathrm{SDS} 30 \%$ and vice versa. The solutions and mixtures of surfactants $(50 \mathrm{~mL})$ were added to $30 \mathrm{mg}$ of ZnNPs, sonicating for 15 min which led to the formation of dispersions of ZnNPs in surfactants. The percentage of the different components in the final dispersion were (45:50:5, SDS:CTAB:ZnNPs). The suspensions were then aged overnight at room temperature. The appropriate amount of dispersed ZnNPs solution was passed through a nylon filter $(1 \mathrm{~cm}$ diameter) and the ZnNPs were adsorbed.

\subsection{Analytical Response Measurements}

2.4.1. Determination of Nitrites or Nitrates Adding the Griess Reagents in Solution

The determination of nitrites in the solution was carried out by adding $0.5 \mathrm{~mL}$ of Griess reagent solution and $0.5 \mathrm{~mL}$ of nitrite solution. After $8 \mathrm{~min}$, the absorbance at $540 \mathrm{~nm}$ was measured. To determinate nitrates, prior to the Griess reaction, the appropriate volume of dispersed ZnNPs solution as a reducing agent was added (leaving $3 \mathrm{~min}$ ).

\subsubsection{Analytical Response Measurements Adding the Sensor Membrane}

The measurement of nitrites by using the synthesized composite was performed by introducing the PDMS-membranes in a vial containing $0.5 \mathrm{~mL}$ of citric acid $(330 \mathrm{mM})$ and adding the $0.5 \mathrm{~mL}$ of standard solution of $\mathrm{NO}_{2}^{-}$. To determinate nitrates, prior to the Griess reaction, the appropriate volume of dispersed $\mathrm{ZnNPs}$ or nylon membrane with ZnNPs as a reducing agent was added. The smartphone images were captured and processed [31]. 


\subsubsection{Reference Methods: Potentiometric Measurement and UV at $220 \mathrm{~nm}$}

Potentiometric method based on the employment of $\mathrm{NO}_{3}^{-}$ISE electrode was used [28]. In water vegetable samples a saturated solution of $\mathrm{AgNO}_{3}$ was added to avoid the presence of $\mathrm{Cl}^{-}$in the samples (vegetable samples). Any sample treatment was performed to determine $\mathrm{NO}_{3}^{-}$in water samples being the spectrophotometric UV method the method used as reference [32].

\subsubsection{Analytical Response Measurements in 96-Well Multiplate}

In this case a microplate of 96 wells was used. Firstly, the reduction reaction was carried out and the dispersion or the nylon with ZnNPs were place in the well. The composite was place at the bottom of the well and $150 \mu \mathrm{L}$ of citrate buffer $(330 \mathrm{mM})$ and $150 \mu \mathrm{L}$ of standard or sample were added.

\subsection{Analysis of Real Samples}

Different types of water samples were analyzed (drinking and tap water and waters from different places of Valencia Community and from irrigation canals) and water from canned and boiled fresh vegetables (spinach and chard).

Wells water, well diluted in proportion 1:3, and irrigation canal water were directly analyzed. Drinking and tap water were processed directly without any previous treatment while river and lake samples were diluted depending on their concentration. The lake sample was diluted to $100 \mathrm{~mL}$ and river water-1 $\mathrm{mL}$ diluted to $10 \mathrm{~mL}$. If the samples contained particles, they were first filtered. Canned chard and spinach were purchased from the supermarket. Afterwards, $1 \mathrm{~mL}$ of the liquid solution was taken and diluted to $100 \mathrm{~mL}$ with nanopure water. The diluted solution was used for further analysis. Fresh spinach and chard were cleaned with water and cut in pieces. For the experiments, $140 \mathrm{~g}$ of fresh spinach or $280 \mathrm{~g}$ of fresh chard were boiled in $350 \mathrm{~mL}$ of nanopure water for $20 \mathrm{~min}$. The vegetables were drained and separated from the liquid. The resulting liquid was diluted to $250 \mathrm{~mL}$ with nanopure water. Then $1 \mathrm{~mL}$ of the diluted solution was taken and diluted to $100 \mathrm{~mL}$. These dilutions were used for further analysis.

\section{Results and Discussion}

\subsection{Study of the Reaction with the Composite}

Our research group has experience in the development of polymeric composites in which derivatizing reagents can be embedded and stabilized in time. In this paper, both reagents involved in Griess reaction were entrapped in PDMS membranes. Taking into account the ratio and the number of reagents used in solution, these reagents were entrapped in a PDMS membrane. In the first set of experiments, the response of PDMS sensors to the $\mathrm{NO}_{2}^{-}$concentration was evaluated. It was observed that when a sensor was introduced into a solution, the reagents (SA and NEDD) were released from the membrane to the solution. No differences in the analytical signals were obtained by entrapping both reagents (SA and NEDD) in the same PDMS composite or in different. Thus, the entrapment in the same membrane was the option selected.

To obtain similar sensitivity to that obtained by performing this reaction in solution, the composition of the membrane was studied. One of the possible drawbacks of PDMS membranes can be the low reagent diffusion; therefore, with the purpose of increasing diffusion, the membranes were doped with TEOS and/or ionic liquid (IL). The addition of TEOS to the membrane improves the hydrophilic character of the membrane [13]. ILs as chemical additives influenced the sol-gel porosity due to the interactions between the components of the polymeric matrix. Based on previous studies realized by Campins et al. [20], the IL selected was 1-Methyl-3-octylimidazolium hexafluorophosphate $\left(\mathrm{OMIM} \mathrm{PF}_{6}\right)$, which is hydrophobic and water-insoluble. This compound was confined into the organic polymeric membrane. The cross-linking sol-gel reaction was initiated upon stirring the mixture and the IL was entrapped as a solid, forming a sponge-like PDMS membrane. Simultaneous $\mathrm{H}$-bonds between $\mathrm{PF}_{6}$ and silica matrix together with imidazolium groups $\pi-\pi$ stacking [33] 
when using $\mathrm{OMIM} \mathrm{PF}_{6}$ provide a high-porosity membrane, which can improve the efficiency of the material for sensing purposes. According to Sasikumar et al. [34], the IL are entrapped in the tight spaces between individual polymer chains or clusters. Physical and chemical interactions between the polymer and $\mathrm{OMIM} \mathrm{PF}_{6}$ can stabilize the ILs in the polymer matrix [35]. The amount of $\mathrm{OMIM} \mathrm{PF}_{6}$ added to the PDMS was lower than $7 \%$ that was the maximum amount allowed to gel properly [20]. Figure 1 shows the SEM image corresponding to the PDMS-TEOS and PDMS-OMIM PF 6 composites. In presence of $\mathrm{OMIM} \mathrm{PF}_{6}$ the SEM image shows the spongelike PDMS structures. Similar results have been achieved by A.I. Horowitz and M.J. Panzer [36] who obtained an asymmetric structure of PDMS polymer with high permeability caused by a decreasing rigidity of the polymer backbone and an increase in void volume available for the diffusion of the permeable molecules. The capabilities of the different synthesized membranes (PDMS/TEOS-SiO ${ }_{2}$ NPs-SA-NEDD,

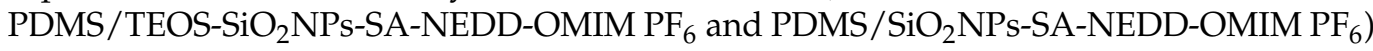
in terms of reagent release were evaluated and compared.
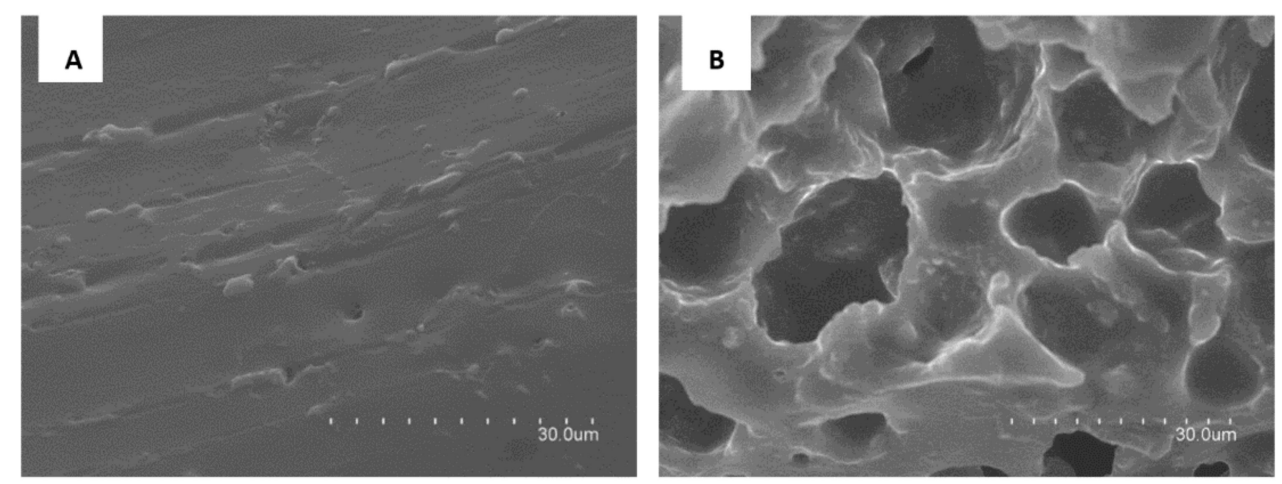

Figure 1. SEM imagens corresponding to the PDMS-TEOS (A) and PDMS-OMIM PF 6 (B) membranes.

The kinetics between $\mathrm{NO}_{2}^{-}$and Griess reagent can be seen in Figure 2. The analytical signal depends on the release of the reagent (SA-NEDD) which in turn depends on the composition of the membrane. The results showed that the analytical responses were higher with the OMIM-PF 6 modified PDMS membrane than with PDMS-TEOS membrane due to the higher reagent diffusion. The use of $\mathrm{OMIM} \mathrm{PF}_{6}$ improved sensibility and response time owing to increase the accessibility and the porosity of the membrane. Thus, based on these results PDMS-OMIM $\mathrm{PF}_{6}$ with both reagents (SA and NEDD) entrapped in the same support were used for further experiments.

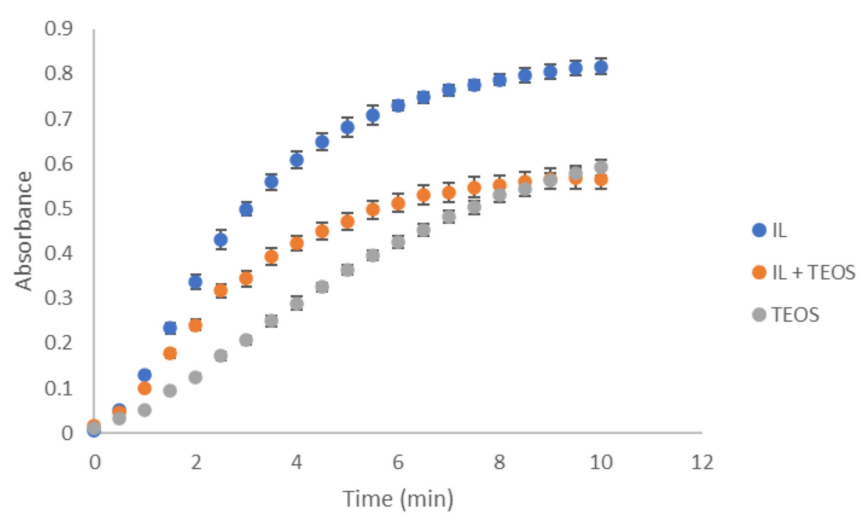

Figure 2. Kinetic study-analytical signals of derivates in solution by using the different type of sensor. $\mathrm{NO}_{2}^{-}$. concentration $1.4 \mathrm{mg} \mathrm{L}^{-1}$.

By using this composite, a kinetic study was carried out in order to determine the time required to reach a plateau. As can be seen in Figure 3a, the analytical signal was 
dependent on nitrite concentration and in all cases a plate was reached at $8 \mathrm{~min}$. According to these results, this time was selected for further experiments. As illustrative example, in Figure $3 b$ are shown the spectra obtained for different nitrite solutions, as well as a picture of the corresponding solutions in presence of the composite. No significant differences were observed between membranes prepared in different batches.
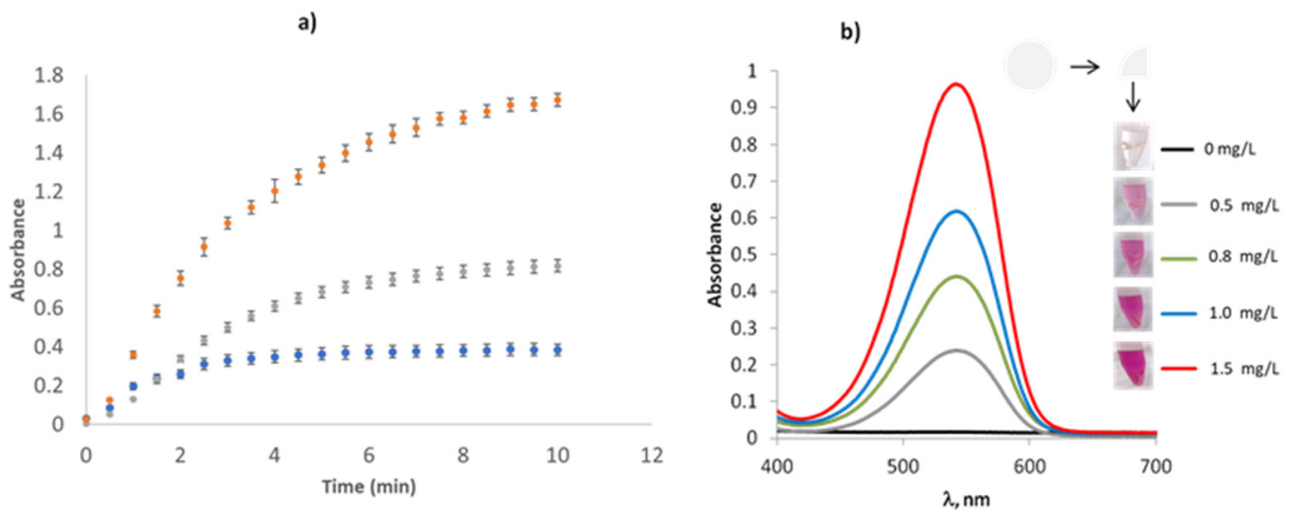

Figure 3. (a) Griess reaction time optimization employed PDMS sensing devices for different nitrite concentrations. (b) Vis spectra of different $\mathrm{NO}_{2}^{-}$solutions employing Griess reagents entrapped in PDMS membranes.

The IR spectra were used to characterize the selected membrane. The observed vibrational wavenumbers of the PDMS $/ \mathrm{SiO}_{2}$ NPs-SA-NEDD-OMIM PF 6 sensor were compared with the PDMS-IL membrane and with the characteristic bands of Griess reagent. As we can see in Figure S1 (red line) several characteristic PDMS bands $\left(2962 \mathrm{~cm}^{-1}, 1256 \mathrm{~cm}^{-1}\right)$ were present in the composition of the PDMS $/ \mathrm{SiO}_{2} \mathrm{NPs}-\mathrm{SA}-\mathrm{NEDD}-\mathrm{OMIM} \mathrm{PF}_{6}$ sensor [37]. The characteristic bands of SA and NEDD were also identified in the proposed sensor. SA were characterized with two bands at 3478 and $3375 \mathrm{~cm}^{-1}$ due to the asymmetric and symmetric stretching vibrations of the $\mathrm{NH}_{2}$ group and one band at $3267 \mathrm{~cm}^{-1}$ due to the symmetric stretching corresponding to the $\mathrm{SO}_{2} \mathrm{NH}_{2}$ group [38]. It was also the characteristic bands between $1600-1400 \mathrm{~cm}^{-1}$ related to $\mathrm{N}-\mathrm{H}$ (d)vibrations. It is possible to see the band around $1300 \mathrm{~cm}^{-1}$ corresponding to $\mathrm{S}=\mathrm{O}$ symmetric. In relation to NEDD, the bands at 3478 and $3375 \mathrm{~cm}^{-1}$ can be glimpsed in a very weak form. Characteristic bands within the range $1600-1400 \mathrm{~cm}^{-1}$ were identified related to stretching $\mathrm{C}=\mathrm{C}$ and bending vibration of N-H [39]. (Supplementary Material Figure S1). Membranes were also characterized by EDX in order to find the elemental composition. In PDMS membranes, C, O, and Si were the majority component. The addition of $\mathrm{OMIM} \mathrm{PF}_{6}$ gave a $\mathrm{F}$ in the composition and when the SA and NED were present in the membrane, beside the components already indicated, appeared a band corresponding to $\mathrm{N}$ (Figure S2).

\subsection{Study of ZnNPs as Reductor Nitrate Agent}

Some procedures have been described in the bibliography to reduce nitrate to nitrite using Zn powder either in batch mode [40] or in FIA mode using a Zn column [24]. In order to perform batch procedures, the nitrate reduction reagents have to be added to the solution. The insolubility of $\mathrm{Zn}$ powder in water solution [41] affects the nitrate reduction reaction, and the reproducibility of the results. Thus, in this paper we propose the use of ZnNPs in order to improve the reduction reaction. One of the limitations of ZnNPs is the low stability of aqueous dispersions. Usually, they present agglomeration which is caused by Van der Waals attraction forces between particles. To disperse NPs in aqueous medium, an external force is needed to overcome the van der Waals attractions and sonication is commonly used to break up agglomerated NPs [42]. In this case, the size of commercial NPs ranged between 40-60 nm, the primary particles were forming agglomerates of micrometers. Sonication was not enough to disperse ZnNPs in water, and surfactants were used. 
Cationic (hexadecyltrimethylammonium bromide-CATB) and anionic surfactants (sodium dodecyl sulphate-SDS) were employed in order to obtain a dispersion of ZnNPs. The solutions of surfactants (CTAB and SDS) are transparent, but in conditions of mixtures with high concentrations produce turbidity, and even precipitation. The non-transparent solutions contained vesicles that are generally stable for a long period of time [43]. According to Tomasic et al. [44] for equal concentrations $(25 \mathrm{mM})$ of both surfactants (CTAB and SDS), precipitate was formed; while for $25 \mathrm{mM} \mathrm{CTAB}$, and $15 \mathrm{mM}$ SDS and vice versa, the vesicles were formed. Based on the above data, mixtures with concentrations lower than $25 \mathrm{mM}$ for CTAB and SDS were prepared. Aqueous solutions with concentrations (15 mM CATB and 17.3 mM SDS) and mixtures in different proportions (0: 100, 30:70, 70:30, 100: 0) of SDS:CTAB respectively were prepared. The ZnNPs were dispersed in all these solutions except in solution $100 \%$ of SDS or CTAB. SDS 30\%-CTAB 70\% was chosen as the final composition for their capacity of forming vesicles (Figure S3A) and its greater stability (more than 1 week) (Figure $4 \mathrm{a}-\mathrm{c}$ ). The presence of these structures allowed stable dispersion (Figure S3B). It should be noted that dispersion of Zn powder under the same conditions was not achieved (Figure $4 \mathrm{~b}$ ). The size of the ZnNPs in the $30 \%$ SDS-70\%CTAB dispersion was checked by measuring the size distribution using Dinamic Light Scattering (DLS). As shown in Figure 4c, the hydrodynamic size of ZnNPs was around $100 \mathrm{~nm}$ by using (DLS) and $\zeta$-potential was $15 \mathrm{mV}$.

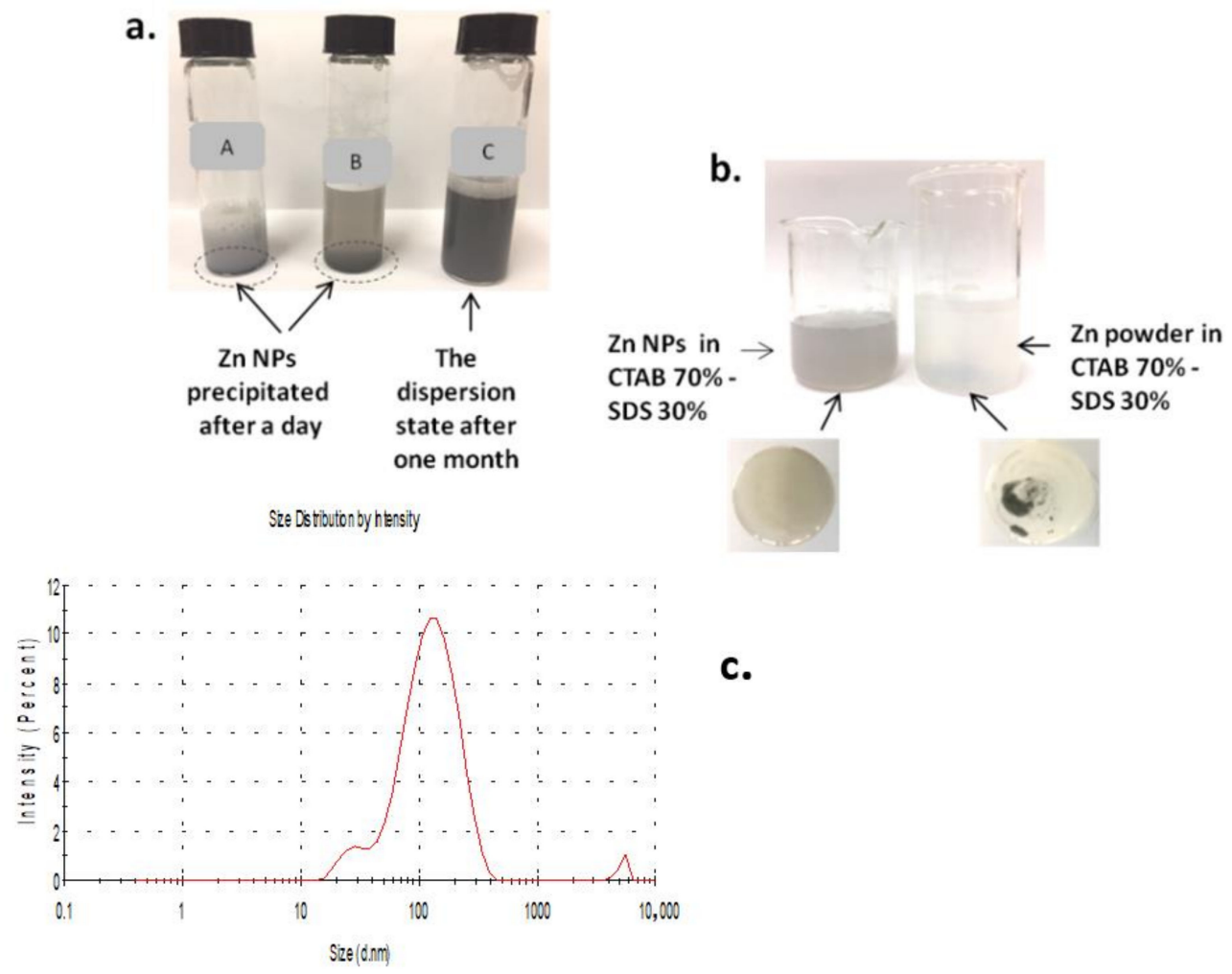

Figure 4. (a) ZnNPs in different proportions of surfactants A-CTAB 30\%-SDS 70\%; B-SDS 100\%; C-CTAB 70\%-SDS 30\%. (b) ZnNPs and Zn power in CTAB-SDS surfactant mixture. (c) Intensity size distribution of the ZnNPs dispersed in the 30\%SDS-70\%CTAB surfactant mixture.

The effect of the amount of ZnNPs in the reduction reaction and in the Griess reaction was evaluated. In order to obtain the satisfactory analytical response, ZnNPs amount required to perform the reduction reaction was studied. As can be seen in Figure 5a, $0.12 \mathrm{mg} /$ per assay (or $200 \mu \mathrm{L}$ of ZnNPs dispersion) were needed to reach the plateau. Remarkably, this amount was lower than that needed when NPs were not dispersed $(0.625 \mathrm{mg})$. Concerning the time required for the reduction reaction, in Figure $5 \mathrm{~b}$ is shown the kinetic graph. The results indicated that the reaction was completed within $2 \mathrm{~min}$, and 
the absorbance did not change over time. No interferences were observed by the presence of the $\mathrm{ZnNPs}$ dispersion on the Griess reaction. These results indicated that the dispersed ZnNPs favored the reaction and reduced the amount and time required. To perform the reduction, in this approach $\mathrm{ZnNPs}$ dispersion $(200 \mu \mathrm{L})$ were added to the standard $\mathrm{NO}_{3}^{-}$ solutions or samples. After $3 \mathrm{~min}$, the reagent membrane was added to the solution and the total time to carry out both reactions was $10 \mathrm{~min}$. The reaction product (azo compound formation) was stable over time.

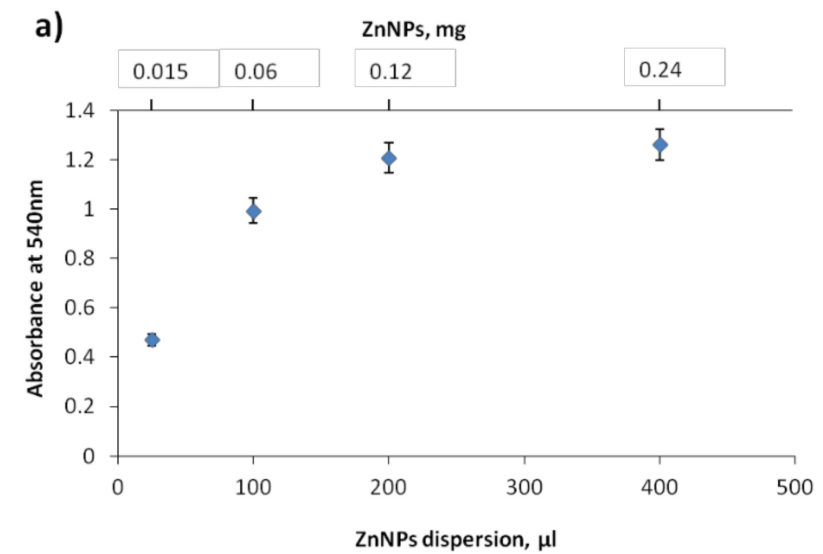

b)

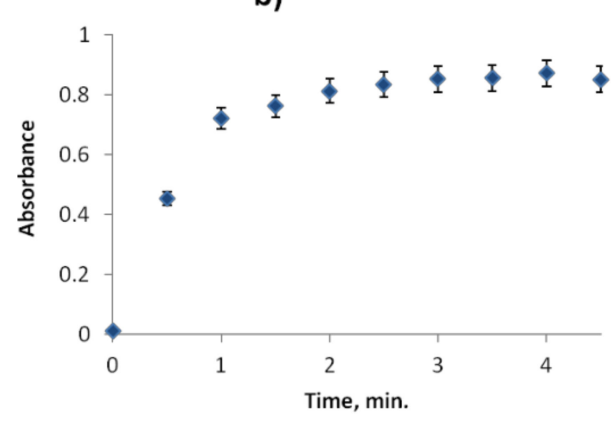

c)

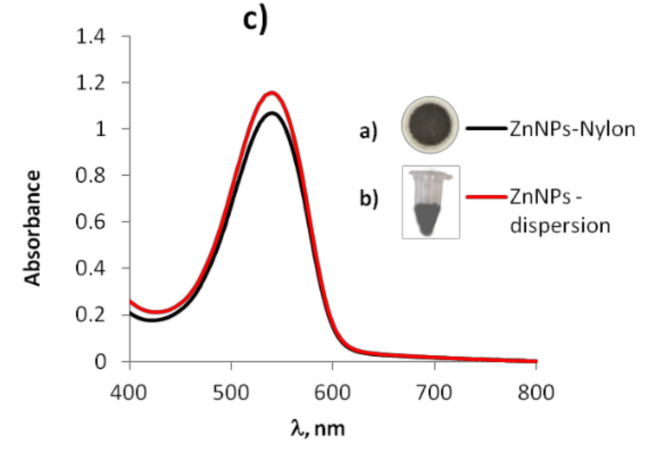

Figure 5. (a) ZnNPs amount optimization in the reduction reaction of nitrate $\left(24 \mathrm{mg} \mathrm{L}^{-1}\right)$ to nitrite. (b) Reduction reaction time optimization of nitrate $\left(20 \mathrm{mg} \mathrm{L}^{-1}\right)$ to nitrite. (c) Analytical responses using ZnNPs-nylon and ZnNPs-dispersion.

Additionally, a more advance strategy relies on the immobilization of ZnNPs on a nylon membrane ( $0.45 \mu \mathrm{m}$ porous size). To this end, $200 \mu \mathrm{L}$ of a $\mathrm{ZnNPs}$ surfactant dispersion were passed through the nylon membrane. The vesicles ad the ZnNPs were retained on the membranes. This membrane was used for reducing $\mathrm{NO}_{3}^{-}$. The analytical responses were slightly lower than those obtained with ZnNPs dispersion in surfactant (Figure 5c). However, the stability of ZnNPs was improved compared with liquid dispersion (more than 1 month) than in the dispersion. In this approach, both membranes were added at the same time, and acidic medium was required to release $\mathrm{ZnNPs}$ from the nylon membrane to the solution.

\subsection{Transferability to 96 Wells in a Microplate}

In order to develop a method in multiplex format, this approach was transferred to a 96 wells microplate. The size of the membrane used was reduced according to the volume used. In this case, the absorbance could be measured by a microplate reader or by RGB coordinates obtained from the digital images captured by using a smartphone $[17,31]$.

To determine $\mathrm{NO}_{2}^{-}$, the membrane was fitted at the bottom of the plate and then the citric acid and the sample were added. Two different formats of microplate were tested, transparent and white (Figure 6). The best results were obtained with white plates, and the RGB selected was G (Green) due to the improvement of sensibility and linearity. 
The experiments were performed by using dairy light or LEDs source (white box), and better results were obtained by controlling the light conditions, in this case by using LEDs. Concerning to the reduction of $\mathrm{NO}_{3}^{-}$to $\mathrm{NO}_{2}^{-}$both methodologies (addition of the ZnNPs dispersion or addition of nylon with $\mathrm{ZnNPs}$ retained) provided good results. Figure 7 shows a calibration curve of both analytes, $\mathrm{NO}_{3}^{-}$and $\mathrm{NO}_{2}^{-}$, under the optimal conditions. The response was obtained at $1 \mathrm{~min}$ ) for $\mathrm{NO}_{2}^{-}$, and $10 \mathrm{~min}$ for $\mathrm{NO}_{3}^{-}$, respectively. These responses were stable for at least $120 \mathrm{~min}$, and the presence of ZnNPs did not affect the assay stability.

a)

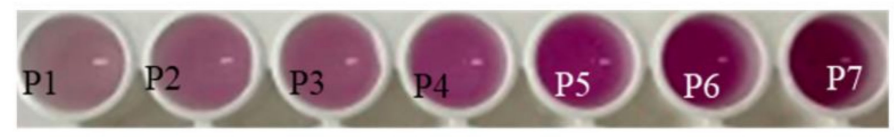

b)

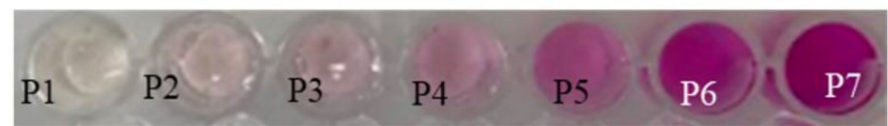

Figure 6. Images corresponding to different concentrations of $\mathrm{NO}_{2}^{-}$(from $0.01 \mathrm{mg} \mathrm{L}^{-1}$ to $2.7 \mathrm{mg} \mathrm{L}^{-1}$ ) in 96-microplate of $\mathrm{NO}_{2}^{-}$. (a) white microplate; (b) transparent microplate.

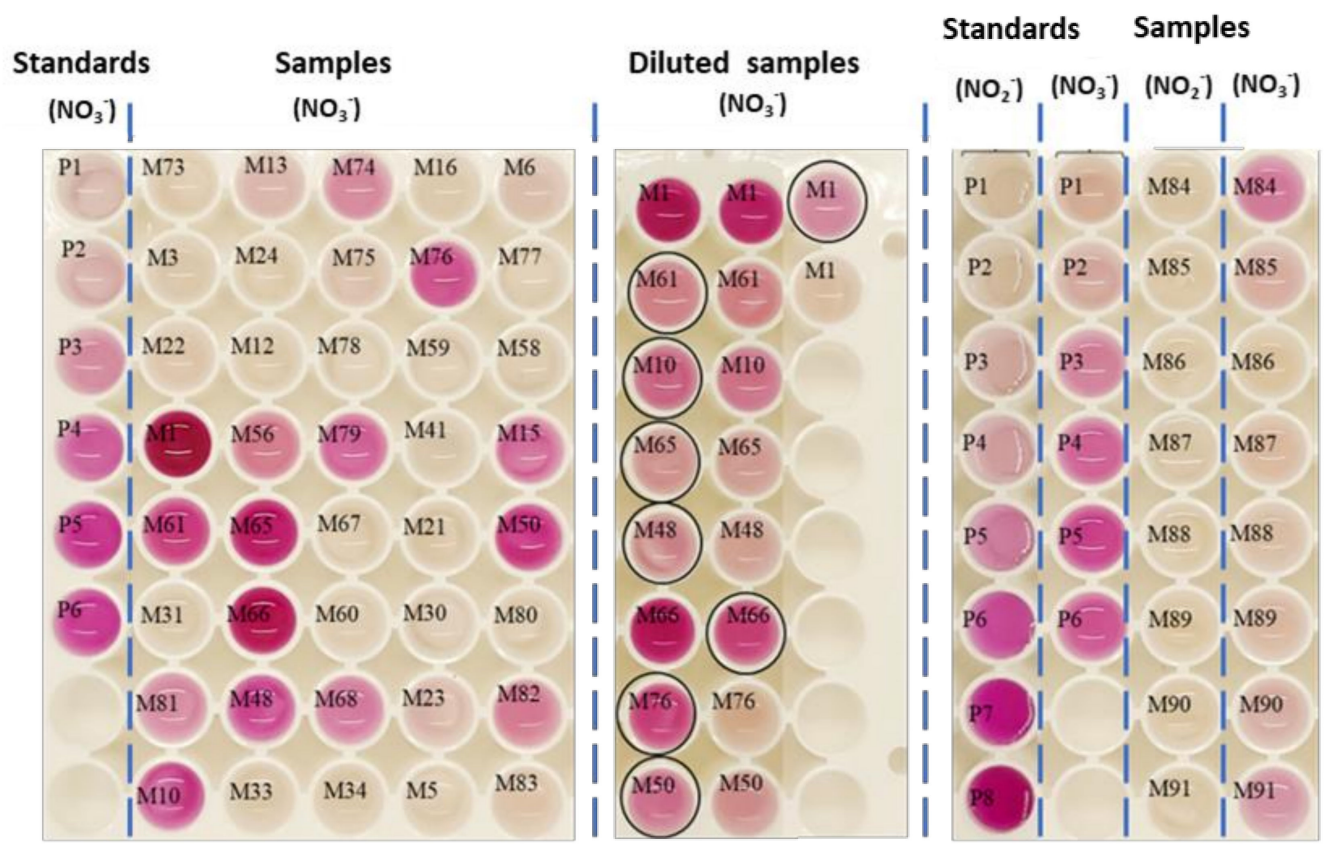

Figure 7. Calibration curve in 96-microplate of $\mathrm{NO}_{2}^{-}$(from $0.01 \mathrm{mg} \mathrm{L}^{-1}$ to $2.7 \mathrm{mg} \mathrm{L}^{-1}$ ) (P). $\mathrm{NO}_{3}^{-}$(1.6 to $\left.25 \mathrm{mg} \mathrm{L}^{-1}\right)(\mathrm{P})$. Response to $\mathrm{NO}_{2}^{-}$and $\mathrm{NO}_{3}^{-}$in different real samples (M).

\subsection{Quality Assurance/Quality Control}

The calibration curve for nitrate or nitrate determination were established under the different methodologies used. Linear range, sensitivity, precision detection LODs and LOQs are shown in Table 2 . The obtained values indicate that this procedure provided adequate linearity in the working concentration interval $0.04-2.5 \mathrm{mg} \mathrm{L}^{-1}$ and $1.61-30 \mathrm{mg} \mathrm{L}^{-1}$ for the nitrite and nitrate, respectively (Figure S4). The LOD was calculated as 3.s/sensitivity, where $s$ is the blank standard deviation [45], being 0.01 and $0.5 \mathrm{mg} \mathrm{L}^{-1}$ for nitrite and nitrate, respectively. The LOQ was calculated as $10 \mathrm{Sa} / \mathrm{b}$ are also listed in Table 2. Inter day and intraday relative standard deviation (\%RSD) was calculated using sensors synthesized in the same batch. Using the solution method, intraday \%RSD were 0.12 and 0.2 , for nitrite and nitrate, respectively, while they were 0.4 and 0.7 using the sensor membrane. These 
results indicated satisfactory precision. In addition, a batch-to-batch precision study was performed. For this aim, the responses of the three sensors prepared in three different batches under identical conditions were obtained. The batch-to-batch interday \%RSD values were 1.6 and 6.2 for nitrite and nitrate, respectively. The low \%RSD values obtained gave evidence that the proposed sensors were precise for their practical application.

Table 2. Figures of merites for nitrite and nitrate. (a) All the reagents in solution; (b) by using the reagents entrapped in PDMS composite and ZnNPs dispersed; (c) by using the reagents entrapped in PDMS composite and ZnNPs retained in nylon.

\begin{tabular}{|c|c|c|c|c|c|c|c|}
\hline & \multicolumn{4}{|c|}{ Linearity $(y=a+b x)\left(\mathrm{mg} \mathrm{L}^{-1}\right)$} & \multicolumn{2}{|c|}{ Precision RSD (\%) } & \multirow{2}{*}{$\begin{array}{c}\text { LOD } \\
\left(\mathrm{mg} \cdot \mathrm{L}^{-1}\right)\end{array}$} \\
\hline & $\mathbf{a} \pm \mathrm{s}_{\mathbf{a}}$ & $\mathbf{b} \pm \mathbf{s}_{\mathbf{b}}$ & $\mathbf{R}^{2}$ & $\begin{array}{c}\text { Linear } \\
\text { Interval } \\
\left(\mathrm{mg} \cdot \mathrm{L}^{-1}\right)\end{array}$ & $\begin{array}{c}\text { Intraday } \\
(n=3)\end{array}$ & $\begin{array}{c}\text { Interday } \\
(n=3)\end{array}$ & \\
\hline \multicolumn{8}{|l|}{ NITRITE } \\
\hline (a) Solution & $0.007 \pm 0.003$ & $0.661 \pm 0.004$ & 0.99 & $0.02-1.5$ & 0.12 & 0.9 & 0.005 \\
\hline (b) Sensor & $0.0035 \pm 0.009$ & $0.551 \pm 0.007$ & 0.99 & $0.04-2.7$ & 0.4 & 1.6 & 0.01 \\
\hline (b) RGB (green) & $0.062 \pm 0.013$ & $0.550 \pm 0.004$ & 0.99 & $0.09-1.3$ & 1.1 & 7.2 & 0.03 \\
\hline $\begin{array}{l}\text { (b) RGB (green) } \\
\text { multiplate }\end{array}$ & $0.079 \pm 0.013$ & $0.56 \pm 0.08$ & 0.99 & $0.02-2.7$ & 1.3 & 4.3 & 0.01 \\
\hline \multicolumn{8}{|l|}{ NITRATE } \\
\hline (a) Solution & $0.028 \pm 0.013$ & $0.056 \pm 0.001$ & 0.99 & $0.3-30$ & 0.2 & 4.3 & 0.1 \\
\hline (b) Sensor & $0.034 \pm 0.007$ & $0.0409 \pm 0.005$ & 0.99 & $1.6-30$ & 0.7 & 5.8 & 0.5 \\
\hline (c) Sensor & $0.031 \pm 0.008$ & $0.038 \pm 0.0004$ & 0.99 & $1.6-30$ & 0.2 & 6.2 & 0.5 \\
\hline (b) RGB (green) & $0.114 \pm 0.013$ & $0.052 \pm 0.003$ & 0.99 & $2.8-25$ & 1.1 & 7.2 & 0.8 \\
\hline $\begin{array}{l}\text { (b) RGB (green) } \\
\text { Microplate }\end{array}$ & $0.04 \pm 0.013$ & $0.0532 \pm 0.004$ & 0.97 & $0.7-20$ & 0.8 & 7.0 & 0.2 \\
\hline
\end{tabular}

The analytical responses of mixtures of nitrite/nitrate were also evaluated. In order to determine both analytes, the response of the nitrite was measured first using one aliquot of the sample. A second aliquot was required to determine nitrate. When both analytes were determined in the same sample aliquot, no interference of the ZnNPs was detected in the nitrite response, and the responses of nitrite and nitrate (as nitrite) were additive.

On the other hand, the proposed assay allowed determining the concentration quantitatively by measuring the RGB components (Table 2) or semi-quantitatively by visual observation comparing the color solution with a color comparison chart. Similar responses were achieved for the single assay and for the microplate assay.

\subsection{Storage Conditions, Stability, and Reusability}

The sensor stability as a function of time and the environmental conditions was tested. Sensors kept at room temperature and protected from light and air exposition, were tested in a period of 60 days. In these conditions the sensors were totally stable. When the sensors were stored at $4{ }^{\circ} \mathrm{C}$ they were stable for at least 6 months. Figure S5 shows the signal of a given concentration of $\mathrm{NO}_{2}^{-}$by using prepared sensors of different ages ( 0 months, 4 months, and 6 months). As can be seen, the signals were similar which meant that the reagents were stable in the PDMS supports. No differences between different synthesis were observed. The RSD\% corresponding to three syntheses was $<10 \%(n=9)$. To evaluate the reusability, the sensor was employed with different nitrite solutions. Although the response was positive in all cases, the sensitivity was lower as the number of uses increased. Those results indicated that they were a single use. 


\subsection{Application to Real Samples}

The potential utility of the proposed methodology for the determination of nitrate or nitrite in real samples (different types of real waters and liquid government from the chard and spinach canned and water from boiled vegetables) have been tested. The multiplate format was used for different water samples (drinking tap and river). As the samples contained particulate matter, the effect of filtering the samples on the nitrite or nitrate response was studied. For this purpose, aliquots of samples were first filtered and compared with non-filtered solutions. The results obtained indicated that the sample filtration did not affect the results. According to these results, samples were filtered in case of the existence of particles. In Table 3 are shown the concentrations obtained for water samples. Relatively high concentration of $\mathrm{NO}_{3}^{-}$was obtained for the irrigation water compared with the other samples. These results were in concordance with those obtained by using a comparative method. Concerning the amount of $\mathrm{NO}_{2}^{-}$obtained in these samples, the found concentration was below the LODs.

Table 3. Found concentrations of $\mathrm{NO}_{3}^{-}$in different real samples (irrigation water samples, water from canned and boiled fresh green vegetables, river, drinking and tap water). Recoveries corresponding to nitrate (spiled samples $\mathrm{NO}_{3}^{-} 5 \mathrm{mg} \mathrm{L}^{-1}$ ) fortified samples. Comparative method ${ }^{\text {(a) }} \mathrm{UV}$ molecular spectrophotometry, ${ }^{(b)} \mathrm{NO}_{3}^{-}$ISE electrode. $\left({ }^{*}\right) 96$ multiplate assay.

\begin{tabular}{|c|c|c|c|c|}
\hline \multirow{2}{*}{ Samples } & & \multicolumn{2}{|c|}{$\begin{array}{l}\text { Found Concentration } \\
\mathrm{NO}_{3}^{-}\left(\mathrm{mg} \mathrm{L}^{-1}\right)(n=3)\end{array}$} & \multirow[t]{2}{*}{ Recovery (\%) } \\
\hline & & $\begin{array}{l}\text { Proposed } \\
\text { Method }\end{array}$ & $\begin{array}{l}\text { Comparative } \\
\text { Method }\end{array}$ & \\
\hline \multirow[t]{3}{*}{ Irrigation water } & Chanel & $69.2 \pm 0.9$ & $67.13 \pm 0.2^{(a)}$ & $97.2 \pm 0.2$ \\
\hline & Well & $21.42 \pm 0.05$ & $21.6 \pm 0.1^{(\mathrm{a})}$ & $100.5 \pm 0.5$ \\
\hline & Well & $2.79 \pm 0.01$ & - & - \\
\hline \multirow{2}{*}{ Canned vegetables } & Chard & $1103 \pm 60$ & $1210 \pm 90^{(b)}$ & $103.9 \pm 0.4$ \\
\hline & Spinach & $810 \pm 40$ & - & $107.3 \pm 0.2$ \\
\hline \multirow{2}{*}{ Fresh vegetables } & Chard & $1600 \pm 100$ & $1700 \pm 70^{(b)}$ & $93.0 \pm 0.4$ \\
\hline & Spinach & $990 \pm 40$ & $980 \pm 70^{(b)}$ & $104.0 \pm 0.5$ \\
\hline \multirow{9}{*}{$\begin{array}{l}\text { Drinking water }(*) \\
\text { Tap water }\left(^{*}\right)\end{array}$} & M84 & 10.6 & & \\
\hline & M85 & 2.8 & & \\
\hline & M86 & $<\mathrm{LOD}$ & & \\
\hline & M87 & 1.8 & & \\
\hline & M88 & 2.0 & & \\
\hline & M89 & 2.0 & & \\
\hline & M90 & 2.2 & & \\
\hline & M81 & 7.0 & & \\
\hline & M91 & 6.0 & & \\
\hline River water $(*)$ & M65 & 74 & & \\
\hline Lake water $\left(^{*}\right)$ & M1 & 204 & & \\
\hline
\end{tabular}

Regarding the liquid of the canned and the boiled water obtained from vegetables, two different samples of two different green leaves vegetables were analyzed. The samples were diluted in order to be analyzed. The concentrations of nitrate found in the samples are shown in Table 3. The accuracy was evaluated by fortifying the samples with different nitrate concentrations. For all the concentrations studied, the recoveries were about $100 \%$ with relative errors lower than $10 \%$. Based on these results we could conclude that no matrix effect was observed in these samples and the concentration could be directly determined by using external calibration. Validation of this methodology was carried out by comparing the results with those obtained using an ISE electrode and UV spectrophotometric methods [20]. For a level of significance of $95 \%$, there were not statistically differences between the results of both methods. The found concentrations in the liquids from canned vegetables and boiled fresh vegetables were lower than those stablished in the CE legislation [6] that establishes 
a maximum of $2000 \mathrm{mg}$ of nitrate per $\mathrm{kg}$ of vegetable. However, these results indicated that the consumption of the liquid from canned vegetables or from the boiled water from fresh vegetables can result in being a high source of nitrates in the diet. Regarding the $\mathrm{NO}_{2}^{-}$ concentration, none of the samples analysed presented concentrations above the LODs of the method.

Drinking and tap water were also analyzed using the multiplate format. The results are shown in Figure 7 and in Table 3. The concentration of nitrite was lower than the limit of detection in all analyzed samples. Low concentrations were found in drinking and tap waters. A dilution of the sample was required for samples M1 (lake water) and M65 (river water collected after depuration station). The concentrations of $\mathrm{NO}_{2}^{-}$found in these samples were 0.05 and $0.4 \mathrm{mg} \mathrm{L}^{-1}$, respectively.

\subsection{Comparison with Other Methods}

To illustrate the advantages of the developed approach, a comparative study of the proposed method with other previously proposed has been performed (Table 4). Most of the methodologies proposed in the literature use Griess reagents in solution. The use of PDMS membranes enhances the reagent stability, avoids manipulation of reagents, and improves the dosage. Therefore, method sustainability is improved.

Table 4. Main analytical properties of different procedures described in the literature for $\mathrm{NO}_{2}^{-} / \mathrm{NO}_{3}^{-}$ -determination. (a) $\mathrm{NO}_{2}^{-}$, (b) $\mathrm{NO}_{3}^{-} \cdot\left(^{*}\right)$ the greater the number of asterisks, the greater the parameter.

\begin{tabular}{|c|c|c|c|c|c|c|c|}
\hline \multirow{3}{*}{$\begin{array}{l}\text { Analyte/ } \\
\text { Sample }\end{array}$} & \multirow{3}{*}{ Procedure } & \multicolumn{5}{|c|}{ Evaluation } & \multirow[b]{3}{*}{ Reference } \\
\hline & & \multicolumn{2}{|c|}{ Analytical Parameters } & \multicolumn{2}{|c|}{ Green Points } & \multirow{2}{*}{$\begin{array}{c}\text { Economical Points } \\
\text { Reagent } \\
\text { Consumption } \\
\text { Personal Time } \\
\text { Instrument }\end{array}$} & \\
\hline & & $\begin{array}{l}\text { Analytical } \\
\text { Time/ } \\
\text { Robustez }\end{array}$ & $\begin{array}{c}\text { Figures of Merits } \\
\text { LODs/ } \\
\text { Dynamic Range }\end{array}$ & $\begin{array}{l}\text { Footprint Kg } \\
\mathrm{CO}_{2} / 100 \\
\text { Samples }\end{array}$ & Waste & & \\
\hline $\mathrm{NO}_{3}^{-}$(water) & $\begin{array}{c}\text { Nitrate Reduction- } \\
\text { column } \mathrm{Zn} \text { granules } \\
(0.15-0.40 \mathrm{~mm}) 8 \mathrm{~cm} 3 \mathrm{~min} . \\
\text { Derivatization Griess- solution } \\
\text { Analytical signal- } \\
\text { Absorbance }\end{array}$ & $\begin{array}{l}\text { FIA in lab or } \\
\text { in situ } \\
\text { (40 samples } / \mathrm{h})\end{array}$ & $\begin{array}{c}0.006 \mathrm{mg} \mathrm{L}^{-1} \\
0.04-0.3 \mathrm{mg} \mathrm{L}^{-1}\end{array}$ & 0.25 & $\begin{array}{l}\text { High } \\
\text { amount of } \\
\text { waste } \\
\text { (Continuous } \\
\text { flow) }\end{array}$ & $\begin{array}{l}\text { Reagents: }{ }^{* * *} \\
\text { Personal: } \\
\text { Instrument: } \\
* * *\end{array}$ & [24] \\
\hline $\begin{array}{c}\mathrm{NO}_{2}^{-} / \mathrm{NO}_{3}^{--} \\
\text {(water and } \\
\text { food } \\
\text { samples) }\end{array}$ & $\begin{array}{l}\text { Nitrate Reduction-Zn powder } \\
(0.1 \mathrm{~g} / \text { sample })-5 \mathrm{~min} \text { volume } \\
100 \mathrm{~mL} \\
\text { Derivatization Griess-10 min } \\
\text { Analytical signal-Absorbance }\end{array}$ & Batch & 3 to $5 \mathrm{mg} \mathrm{Kg}^{-1}$ & 5.99 & $\begin{array}{c}\text { High } \\
\text { volumes used }\end{array}$ & $\begin{array}{l}\text { Reagents: *** } \\
\text { Personal: } * * * \\
\text { Instrument: ** }\end{array}$ & [40] \\
\hline $\mathrm{NO}_{3}^{-}$(water) & $\begin{array}{l}\text { Nitrate Reduction-Zn powder } \\
(150 \mu \mathrm{m})(25 \mathrm{mg} / \mathrm{sample}) 10 \mathrm{~min} \\
\text { Derivatization Griess-solution } \\
\text { Anaytical signal-Absorbance }\end{array}$ & Batch & $\begin{array}{c}0.5 \mathrm{mg} \mathrm{L}^{-1} \\
0.5-45 \mathrm{mg} \mathrm{L}^{-1}\end{array}$ & 0.23 & $\begin{array}{c}10 \mathrm{~mL} \\
\text { sample } / 1 \mathrm{~min} \\
\text { reagent }\end{array}$ & $\begin{array}{l}\text { Reagents: ** } \\
\text { Personal: *** } \\
\text { Instrument: ** }\end{array}$ & [41] \\
\hline $\begin{array}{l}\text { (a) } \mathrm{NO}_{2}^{-} \text {(b) } \\
\mathrm{NO}_{3}^{--} \rightarrow \\
\text { (Synthetic, } \\
\text { tap, pond, } \\
\text { and mineral } \\
\text { water) }\end{array}$ & $\begin{array}{c}\text { Inkjet printing with AKD } \\
\text { Zn suspension prepared by mixing } \\
500 \mathrm{mg} \text { of } \mathrm{Zn} \text { dust }(<10 \mu \mathrm{m}) \\
1 \mathrm{mg} / \mathrm{sample}(75 \mathrm{~s}) \\
\text { Derivatization Griess- } \mu \mathrm{PAD} \\
\text { paper support }(3-7 \mathrm{~min}) \\
\text { Analytical signal-scanned } \\
\text { imagens processed }\end{array}$ & $\begin{array}{l}\text { In situ } \\
\text { Microfluidic } \\
\text { Sensor } \\
\text { Stable for } \\
30 \text { days } \\
\text { Stored in } \\
\text { vacuum at } \\
\leq-20^{\circ} \mathrm{C} \text { ) }\end{array}$ & $\begin{array}{l}\text { (a) } 0.04 / \text { (b) } 1.2 \mathrm{mg} \mathrm{L}^{-1} \\
0.5-6.9 \mathrm{mg} \mathrm{L}^{-1(\mathrm{a})} \\
3.1-62 \mathrm{mg} \mathrm{L}^{-1(\mathrm{~b})}\end{array}$ & $\begin{array}{l}9.45 \\
\text { In the } \\
\text { fabrication of } \\
\text { the sen- } \\
\text { sor/scanner }\end{array}$ & $\begin{array}{l}\text { Low } \\
\text { consumption } \\
\text { of reagents } \\
(\mu \mathrm{L})\end{array}$ & $\begin{array}{l}\text { Reagents: * } \\
\text { Personal: * } \\
\text { Instrument: ** }\end{array}$ & {$[30]$} \\
\hline $\begin{array}{l}\text { (a) } \mathrm{NO}_{2}^{-} / \text {(b) } \\
\mathrm{NO}_{3}^{-}\end{array}$ & $\begin{array}{l}\text { Nitrate Reduction-Dispersion of } \\
\text { ZnNPs (0.12 mg/sample) } 3 \mathrm{~min} \\
\text { Derivatization Griess-5 min, } \\
\text { solution } \\
\text { Analytical signal-processed } \\
\text { imagens (RGB) or Absorbance }\end{array}$ & $\begin{array}{l}\text { In situ } \\
\text { Reagents } \\
\text { supported in } \\
\text { PDMS } \\
\text { Stable for } \\
\text { more than } 6 \\
\text { moths }\end{array}$ & $\begin{array}{l}\text { (a) } 0.01 / \text { (b) }^{\text {(b) }} 0.5 \mathrm{mg} \mathrm{L}^{-1} \\
0.04-2.5 \mathrm{mg} \mathrm{L}^{-1} \text { (a) } \\
1.6-30 \mathrm{mg} \mathrm{L}^{-1(\mathrm{~b})}\end{array}$ & 0.028 & $\begin{array}{l}\text { Low } \\
\text { consumption } \\
\text { of reagents } \\
(\mu \mathrm{L})\end{array}$ & $\begin{array}{l}\text { Reagents: * } \\
\text { Personal: * } \\
\text { Instrument: * }\end{array}$ & $\begin{array}{c}\text { Proposed } \\
\text { method }\end{array}$ \\
\hline \multicolumn{8}{|l|}{$\begin{array}{l}\text { Reference } \\
\text { methods }\end{array}$} \\
\hline $\mathrm{NO}_{3}^{-}$ & $\begin{array}{c}\text { Electrode Nitrate } \\
10 \mathrm{~mL} \text { sample } 10 \mathrm{~mL} \text { of buffer } \\
\left(\mathrm{Al}_{3} \mathrm{SO}_{4}\right)_{3} 17 \mathrm{mg} ; \mathrm{Ag}_{2} \mathrm{SO}_{4} 34.3 \mathrm{mg} \\
\mathrm{H}_{3} \mathrm{BO}_{4} 18.6 \mathrm{mg}, \mathrm{H}_{2} \mathrm{SO}_{3} \mathrm{H} \\
25.4 \mathrm{mg} / \text { per sample }) \\
\text { Analytical signal-Electrochemical }\end{array}$ & $\begin{array}{l}\text { In situ in the } \\
\text { lab } \\
\text { Interferences: } \\
\mathrm{Cl}^{-}, \mathrm{CO}_{3}^{-2} \text {, } \\
\mathrm{NO}_{2}{ }^{-}, \mathrm{CN}^{-} \\
\mathrm{S}^{2-}, \mathrm{Br}^{-}, \mathrm{I}^{-} \\
\mathrm{ClO}_{3}{ }^{-}, \mathrm{ClO}_{4}{ }^{-}\end{array}$ & $\begin{array}{c}0.6 \mathrm{mg} \mathrm{L}^{-1} \\
0.6-620 \mathrm{mg} \mathrm{L}^{-1}\end{array}$ & $1.8 \times 10^{-4}$ & High volumes & $\begin{array}{l}\text { Reagent: }{ }^{* *} \\
\text { Time/sample: } 3 \text { min } \\
\text { Instrumentation: }{ }^{* * *}\end{array}$ & [32] \\
\hline $\mathrm{NO}_{3}^{-}$ & $\begin{array}{l}\text { Absorbance measurement at } \\
220 \mathrm{~nm} \text { and } 275 \mathrm{~nm} \\
\text { Analytical signal-Absorbance }\end{array}$ & $\begin{array}{l}\text { In situ (probes) } \\
\text { In the lab } \\
\text { (batch or FIA) } \\
\text { Interferences: } \\
\text { soaps, } \mathrm{NO}_{2}^{-} \\
\mathrm{Cr}^{6+}\end{array}$ & $\begin{array}{c}0.1 \mathrm{mg} \mathrm{L}^{-1} \\
0.3 \mathrm{a} 30 \mathrm{mg} \mathrm{L}^{-1}\end{array}$ & 0.025 & & $\begin{array}{l}\text { Reagent: } \\
\text { Time/sample: } 1 \text { min } \\
\text { Instrumentation: } * * *\end{array}$ & {$[32]$} \\
\hline
\end{tabular}


The methods proposed in the bibliography that use $\mathrm{Zn}$ as reducer agent employ large amounts to carry out the reaction, ranging from column $(8 \mathrm{~cm}$ filled with Zn granules $(0.15-0.4 \mathrm{~mm})$ to suspensions of $\mathrm{Zn}$ dust $(<10 \mu \mathrm{m})$. Considering this, we propose the use of ZnNPs (particles size around $100 \mathrm{~nm}$ hydrodynamic size). The use of dispersed ZnNPs required a lower amount $(0.12 \mathrm{mg} /$ sample) than non-dispersed solutions or nonnanoparticles suspensions, thus improving the environmental performance. The LODs and dynamic ranges reached by the proposed methodology are similar to other methods and this is properly adjusted to sample concentrations.

In general, this approach is more sustainable, with lower values of carbon footprint and waste generated. From the economical point of view, it required small amounts of reagents, little personal time, and not much instrumentation (a smartphone can be used as the analytical instrument). Compared with reference procedures, such as ionic liquid chromatography (IC), similar LODs were reached, however IC required more time, reagents, and instrumentation. Although LODs reached by ISE electrode are lower than those achieved with the proposed method, analysis time is reduced since no sample pretreatment is necessary. The Griess method has been traditionally applied to $\mathrm{NO}_{3}^{-}$by using $\mathrm{Cd}$ as reducing agent which is highly toxic. Moreover, the approach proposed in this paper allows processing 96 samples simultaneously using RGB coordinates as analytical signal.

\section{Conclusions}

In this work a new approach is proposed for stabilization and dosage of Griess reagent using PDMS membranes with the reagent embedded. The influence of the TEOS and IL $\left(\mathrm{OMIM} \mathrm{PF}_{6}\right)$ on the reagent diffusion are studied. The characterization of the membranes was performed. The PDMS membranes allow to stabilize the reagents for more than six months. Therefore, the use of $\mathrm{ZnNPs}$ as reductor of $\mathrm{NO}_{3}^{-}$to $\mathrm{NO}_{3}^{-}$was studied. Based on these results a quick assay for quantitative determination of nitrate or nitrite in real samples was developed. Nitrite was directly determined by using the Griess reagent membranes while nitrate required a reduction step with ZnNPs. The samples were directly processed, and any sample treatment was required. Good precision ( $\mathrm{RSD}<8 \%$ ) and detection limit of 0.01 and $0.5 \mathrm{mgL}^{-1}$ for $\mathrm{NO}_{2}^{-}$and $\mathrm{NO}_{3}^{-}$, respectively, were achieved. The approach was satisfactorily applied to the determination of $\mathrm{NO}_{2}^{-}$and $\mathrm{NO}_{3}^{-}$in drinking waters, irrigation and river waters, and waters from canned and fresh vegetables. The advantages of the proposed method with respect to other reported in the literature are related to the portability, low cost, short analysis time, which contribute to be a point of need (PON) method. This approach can be considered as a green and sustainable method which can be used for in situ analysis of waters from different sources (environmental waters and food waters). This procedure has been transferred to a 96 well of a multiplate format allowing the analysis of 96 samples simultaneously, using RGB as analytical signal and smartphone as analytical instrument.

Supplementary Materials: The following supporting information can be downloaded at: https: / / www.mdpi.com/article/10.3390/polym14030464/s1. Figure S1: FT-IR spectra of PDMS-IL (blue), PDMS-IL-SA-NEDD (red), SA (grey) and NEDD (black), Figure S2: EDX spectra a) PDMS, b) PDMSIL, c) PDMS-IL-SA-NED, Figure S3: Imagens of optic microscopy for A) solution of SDS:CATB (30:70) by and B) ZnNPs dispersed on solution of SDS:CATB (30:70), Figure S4: Calibration graphs corresponding to the reagents in solution for $\mathrm{NO}_{2}^{-}(1)$ and $\mathrm{NO}_{3}^{-}$(3) and for the sensor for $\mathrm{NO}_{2}^{-}(2)$ and $\mathrm{NO}_{3}^{-}$(4), Figure S5: Absorbance vs. time for different age sensors (0, 4 and 6 months).

Author Contributions: P.C.-F.: Conceptualization, methodology, validation, supervision, writingreview, funding acquisition; C.M.-L.: Conceptualization, methodology, validation, supervision, writing, editing; Y.M.-M.: Conceptualization, methodology, validation, supervision, writing-review, funding acquisition; L.H.: Methodology, investigation, validation, original draft preparation; B.M.-G.: Investigation, validation. All authors have read and agreed to the published version of the manuscript. 
Funding: The authors are grateful to EU (EASME LIFE and CIP ECO-Innovation) LIBERNITRATE. LIFE 16 ENV/ES/000419; EU FEDER and the Gobierno de España MCI-AEI (CTQ2017-90082-P) and the Generalitat Valenciana (PROMETEO 2020/078) and EU FEDER- Generalitat Valenciana (ID-FEDER/2018/049), Universidad de Valencia and II-LaFE (AK-GLUTEN-DETECT-VLC-BIOMED 2020) for the financial support received. L.Hakobyan expresses her gratitude to GV (PROMETEO 2020/078).

Institutional Review Board Statement: Not applicable.

Informed Consent Statement: Not applicable.

Data Availability Statement: The data presented in this study are available on request from the corresponding author.

Acknowledgments: The authors are grateful to the Spanish Ministerio de Economia y Competitividad (EU- FEDER/MINECO), Gobierno de España MCIU-AEI (CTQ2017-90082-P), Generalitat Valenciana (PROMETEO program 2016/109 and 2020/078) and to the EU LIFE funding (LIFE16 ENV/ES/000419), Universidad de Valencia and Instituto de Investigación la FE (AK-gluten detectVLC-BIOMED 2020).

Conflicts of Interest: The authors declare no conflict of interest.

\section{References}

1. Ward, M.H.; Jones, R.R.; Brender, J.D.; De Kok, T.M.; Weyer, P.J.; Nolan, B.T.; Villanueva, C.M.; Van Breda, S.G. Drinking Water Nitrate and Human Health: An Updated Review. Int. J. Environ. Res. Public Health 2018, 15, 1557. [CrossRef] [PubMed]

2. Hsu, J.; Arcot, J.; Lee, N.A. Nitrate and nitrite quantification from cured meat and vegetables and their estimated dietary intake in Australians. Food Chem. 2009, 115, 334-339. [CrossRef]

3. DIRECTIVE 98/83/EC. Quality of Water Intended for Human Consumption. In Official Journal of the European Communitie; European Communitie: Brussels, Belgium, 1998.

4. EPA Regulation. National Primary Drinking Water Regulations. Available online: https://www.epa.gov/ground-water-anddrinking-water/national-primary-drinking-water-regulations (accessed on 12 October 2021).

5. World Health Organization. Nitrate and Nitrite in Drinking-Water: Background Document for Development of WHO. In Guidelines for Drinking-Water Quality, 4th ed.; World Health Organization: Geneva, Switzerland, 2011. Available online: https: / / apps.who.int/iris/bitstream/handle/10665/44584/9789241548151_eng.pdf?sequence=1 (accessed on 12 October 2021).

6. DIRECTIVE 2006/118/EC. Protection of Groundwater Against Pollution and Deterioration. In Official Journal of the European Union; European Union: Brussels, Belgium, 2006.

7. RD 1620/2007 Spanish Regulation, Legal framework for the reuse of treated wastewater. BOE No 294. (2007) 50639-50661. Available online: https:/ / www.iwa-network.org/filemanager-uploads/WQ_Compendium/Database/Selected_guidelines / 042_2.pdf (accessed on 12 October 2021).

8. COMMISSION REGULATION (EC) No 1881/2006. Setting Maximum Levels Certain Contaminants in Foodstuffs. In Official Journal of the European Union; European Union: Brussels, Belgium, 2006.

9. Salehzadeh, H.; Maleki, A.; Rezaee, R.; Shahmoradi, B.; Ponnet, K. The nitrate content of fresh and cooked vegetables and their health-related risks. PLOS ONE 2020, 15, e0227551. [CrossRef] [PubMed]

10. Wang, Q.-H.; Yu, L.-J.; Liu, Y.; Lin, L.; Lu, R.-G.; Zhu, J.-P.; He, L.; Lu, Z.-L. Methods for the detection and determination of nitrite and nitrate: A review. Talanta 2017, 165, 709-720. [CrossRef] [PubMed]

11. Singh, P.; Singh, M.K.; Beg, Y.R.; Nishad, G.R. A review on spectroscopic methods for determination of nitrite and nitrate in environmental samples. Talanta 2019, 191, 364-381. [CrossRef]

12. Griess, P. Bemerkungen zu der Abhandlung der HH. Weselsky und Benedikt “Ueber einige Azoverbindungen”. Eur. J. Inorg. Chem. 1879, 12, 426-428. [CrossRef]

13. Martínez, N.J.; Moliner-Martínez, Y.; Herráez-Hernández, R.; Molins-Legua, C.; Verdu-Andres, J.; Campíns-Falcó, P. Designing solid optical sensors for in situ passive discrimination of volatile amines based on a new one-step hydrophilic PDMS preparation. Sensors Actuators B Chem. 2016, 223, 333-342. [CrossRef]

14. Bocanegra-Rodríguez, S.; Jornet-Martínez, N.; Molins-Legua, C.; Campíns-Falcó, P. Delivering Inorganic and Organic Reagents and Enzymes from Zein and Developing Optical Sensors. Anal. Chem. 2018, 90, 8501-8508. [CrossRef]

15. Rattanarat, P.; Dungchai, W.; Cate, D.M.; Siangproh, W.; Volckens, J.; Chailapakul, O.; Henry, C.S. A microfluidic paper-based analytical device for rapid quantification of particulate chromium. Anal. Chim. Acta 2013, 800, 50-55. [CrossRef]

16. Muñoz-Ortuño, M.; Argente-García, A.; Moliner-Martínez, Y.; Molins-Legua, C.; Campíns-Falcó, P. Polydimethylsiloxane composites containing 1,2-naphtoquinone 4-sulphonate as unique dispositive for estimation of casein in effluents from dairy industries. Anal. Chim. Acta 2015, 873, 31-37. [CrossRef] 
17. Pla-Tolós, J.; Moliner-Martínez, Y.; Molins-Legua, C.; Campíns-Falcó, P. Solid glucose biosensor integrated in a multi-well microplate coupled to a camera-based detector: Application to the multiple analysis of human serum samples. Sensors Actuators B Chem. 2018, 258, 331-341. [CrossRef]

18. Argente-García, A.; Muñoz-Ortuño, M.; Molins-Legua, C.; Moliner-Martínez, Y.; Campíns-Falcó, P. A solid device based on doped hybrid composites for controlling the dosage of the biocide $\mathrm{N}$-(3-aminopropyl)-N-dodecyl-1,3-propanediamine in industrial formulations. Talanta 2016, 147, 147-154. [CrossRef] [PubMed]

19. Bhakta Samir, A.; Borba, R.; Taba, M., Jr.; Garcia.C.D.: Carrilho, E. Determination of nitrite in saliva using microfluidic paper-based analytical devices. Analytica Chimica Acta 2014, 809, 117-122. [CrossRef] [PubMed]

20. Ballester-Caudet, A.; Hakobyan, L.; Moliner-Martinez, Y.; Molins-Legua, C.; Campíns-Falcó, P. Ionic-liquid doped polymeric composite as passive colorimetric sensor for meat freshness as a use case. Talanta 2021, 223, 121778. [CrossRef]

21. Han, J.; Tao, W.; Shuo, L.; Zhi-Ping, Z. Fabrication of porous polymer membrane from polysulfone grafted with acid ionic liquid and the catalytic property for inulin hydrolysis. J. Membr. Sci. 2021, 618, 118742.

22. Didaskalou, C.; Kupai, J.; Cseri, L.; Barabas, J.; Vass, E.; Holtzl, T.; Szekely, G. Membrane-Grafted Asymmetric Organocatalyst for an Integrated Synthesis-Separation Platform. ACS Catal. 2018, 8, 7430-7438. [CrossRef]

23. Wittbrodt, B.T.; Squires, D.A.; Walbeck, J.; Campbell, E.; Campbell, W.; Pearce, J.M. Open-Source Photometric System for Enzymatic Nitrate Quantification. PLoS ONE 2015, 10, e0134989. [CrossRef] [PubMed]

24. Ellis, P.S.; Shabani, A.M.H.; Gentle, B.S.; McKelvie, I.D. Field measurement of nitrate in marine and estuarine waters with a flow analysis system utilizing on-line zinc reduction. Talanta 2011, 84, 98-103. [CrossRef] [PubMed]

25. Hansen, F.; Koroleff, H.P. Determination of nutrients. In Methods Seawater Analysis, 3rd ed.; Grasshoff, K., Ehrhardt, M., Kremling, K., Eds.; Wiley-VCH Verlag GmbH: Weinheim, Germany, 1999; pp. 159-228.

26. Madsen, B. Utilization of flow injection with hydrazine reduction and photometric detection for the determination of nitrate in rain-water. Anal. Chim. Acta 1981, 124, 437-441. [CrossRef]

27. Wang, S.; Lin, K.; Chen, N.; Yuan, D.; Ma, J. Automated determination of nitrate plus nitrite in aqueous samples with flow injection analysis using vanadium (III) chloride as reductant. Talanta 2016, 146, 744-748. [CrossRef]

28. Lin, K.; Li, P.; Ma, J.; Yuan, D. An automatic reserve flow injection method using vanadium (III) reduction for simultaneous determination of nitrite and nitrate in estuarine and coastal waters. Talanta 2019, 195, 613-618. [CrossRef]

29. Martinez-Cisneros, C.; da Rocha, Z.; Seabra, A.; Valdés, F.; Alonso-Chamarro, J. Highly integrated autonomous lab-on-a-chip device for on-line and in situ determination of environmental chemical parameters. Lab Chip 2018, 18, 1884-1890. [CrossRef]

30. Jayawardane, B.M.; Wei, S.; McKelvie, I.; Kolev, S. Microfluidic Paper-Based Analytical Device for the Determination of Nitrite and Nitrate. Anal. Chem. 2014, 86, 7274-7279. [CrossRef]

31. Martínez-Aviño, A.; Molins-Legua, C.; Pilar, C.-F. Scaling the Analytical Information Given by Several Types of Colorimetric and Spectroscopic Instruments Including Smartphones: Rules for Their Use and Establishing Figures of Merit of Solid Chemosensors. Anal. Chem. 2021, 93, 6043-6052. [CrossRef]

32. Rice, L.S.; Baird, E.W.; Eaton, R.B.; Clesceri, A.D. Standard Methods for the Examination of Water and Wastewater (Méto-dos Normalizados para Análisis de Aguas Potables y Residuales), 17th ed.; Díaz de Santos: Madrid, Spain, 2012.

33. Zhou, Y.; Schattka, A.J.H.; Antonietti, M. Room-Temperature Ionic Liquids as Template to Monolithic Mesoporous Silica with Wormlike Pores via a Sol-Gel Nanocasting Technique. Nano Lett. 2004, 4, 477-481. [CrossRef]

34. Sasikumar, B.; Arthanareeswaran, G.; Ismail, A. Recent progress in ionic liquid membranes for gas separation. J. Mol. Liq. 2018, 266, 330-341. [CrossRef]

35. Friess, K.; Jansen, J.C.; Bazzarelli, F.; Izák, P.; Jarmarová, V.; Kačírková, M.; Schauer, J.; Clarizia, G.; Bernardo, P. High ionic liquid content polymeric gel membranes: Correlation of membrane structure with gas and vapour transport properties. J. Membr. Sci. 2012, 415-416, 801-809. [CrossRef]

36. Horowitz, A.I.; Panzer, M.J. Poly(dimethylsiloxane)-Supported Ionogels with a High Ionic Liquid Loading. Angew. Chem. Int. Ed. 2014, 53, 9780-9783. [CrossRef] [PubMed]

37. Prajapat, G.; Gupta, R.; Bhojak, N. Thermal, Spectroscopic and Antimicrobial Properties of Novel Nickel(II) Complexes with Sulfanilamide and Sulfamerazine Drugs. Chem. Sci. Int. J. 2018, 24, 1-13. [CrossRef]

38. Bocanegra-Rodríguez, S.; Jornet-Martínez, N.; Molins-Legua, C.; Campíns-Falcó, P. New Reusable Solid Biosensor with Covalent Immobilization of the Horseradish Peroxidase Enzyme: In Situ Liberation Studies of Hydrogen Peroxide by Portable Chemiluminescent Determination. ACS Omega 2020, 5, 2419-2427. [CrossRef] [PubMed]

39. Refat, M.S.; Adam, A.M.A.; Sharshar, T.; Saad, H.A.; Eldaroti, H.H. Utility of positron annihilation lifetime technique for the assessment of spectroscopic data of some charge-transfer complexes derived from N-(1-Naphthyl)ethylenediamine dihydrochloride. Spectrochim. Acta Part. A Mol. Biomol. Spectrosc. 2014, 122, 34-47. [CrossRef] [PubMed]

40. Merino, L. Development and Validation of a Method for Determination of Residual Nitrite/Nitrate in Foodstuffs and Water After Zinc Reduction. Food Anal. Methods 2009, 2, 212-220. [CrossRef]

41. Murray, E.; Nesterenko, E.P.; McCaul, M.; Morrin, A.; Diamond, D.; Moore, B. A colorimetric method for use within portable test kits for nitrate determination in various water matrices. Anal. Methods 2017, 9, 680-687. [CrossRef]

42. Hak, C.R.C.; Fatanah, D.N.E.; Abdullah, Y.; Sulaiman, M.Y.M. The Effect of Surfactants on the Stability of TiO ${ }_{2}$ Aqueous Suspension. Int. J. Curr. Res. Sci. Eng. Technol. 2018, 1, 172-178. [CrossRef] 
43. Mal, A.; Bag, S.; Ghosh, S.; Moulik, S.P. Physicochemistry of CTAB-SDS interacted catanionic micelle-vesicle forming system: An extended exploration. Colloids Surfaces A Physicochem. Eng. Asp. 2018, 553, 633-644. [CrossRef]

44. Tomašić, V.; Štefanić, I.; Filipović-Vinceković, N. Adsorption, association and precipitation in hexadecyltrimethylammonium bromide/sodium dodecyl sulfate mixtures. Colloid Polym. Sci. 1999, 277, 153-163. [CrossRef]

45. Shrivastava, A.; Gupta, V.B. Methods for the determination of limit of detection and limit of quantitation of the analytical methods. Chron. Young Sci. 2011, 2, 21-25. [CrossRef] 